\title{
\begin{tabular}{l|l} 
Jurnal Eksplorasi Akuntansi \\
Vol. 1, No 3, Seri E, Agustus 2019, Hal 1411-1425
\end{tabular} \mid $\begin{aligned} & \text { ISSN : 2656-3649 (Online) } \\
& \text { http://jea.ppj.unp.ac.id/index.php/jea/issue/view/12 }\end{aligned}$
}

\section{ANALISIS PERBANDINGAN EFISIENSI, KUALITAS ASET, DAN STABILITAS BANK UMUM KONVENSIONAL DAN BANK UMUM SYARIAH YANG MELAKUKAN PEMISAHAN (SPIN-OFF) DI INDONESIA PERIODE TAHUN 2013-2017}

\author{
Uswatun Hasanah ${ }^{1}$, Vanica Serly ${ }^{2}$ \\ 1)Alumni Jurusan Akuntansi Fakultas Ekonomi, Universitas Negeri Padang \\ 2) Jurusan Akuntansi Fakultas Ekonomi, Universitas Negeri Padang \\ *Korespondensi: ndouble125@gmail.com
}

\begin{abstract}
This research aims to compare the efficiency, asset quality, and stability of Islamic banks that do spin-off and conventional banks in Indonesia from 2013 until 2017. The variables used are overhead cost and cost income ratio as efficiency proxy, the loan loss reserves is a proxy of asset quality, and return on asset and equity to asset ratio are proxy of stability. The sampling technique is total sampling. The population in this study amounted to 22 banks. The statistics test used are descriptive statistic, Mann Whitney test, and Independent Sample t-Test. The results showed that there were no significant differences in efficiency and asset quality, but stability was significant difference from 2013-2017.
\end{abstract}

Keywords: Efficiency; Asset Quality; Stability

How to cite (APA $6^{\text {th }}$ style)

Hasanah, U., \& Serly, V. (2019). Analisis Perbandingan Efisiensi, Kualitas Aset, dan Stabilitas Bank Umum Konvensional dan Bank Umum Syariah yang Melakukan Pemisahan (Spin-Off) di Indonesia Periode Tahun 2013-2017. Jurnal Eksplorasi Akuntansi, 1(3), Seri E, 1411-1425.

\section{PENDAHULUAN}

Lembaga keuangan merupakan lembaga yang mengatur jasa keuangan yang diberikankepada nasabah dalam regulasi keuangan yang ditetapkan oleh pemerintah. Bank memiliki pengaruh dalam peningkatan ekonomi. Perbankan di Indonesia dalam menjalankan kegiatan operasional berdasarkan prinsipikehati-hatianiatas asasidemokrasiiekonomi. Pertumbuhan Bank Umum Syariah (BUS)rdiiIndonesiaidmengalamiipeningkatan secara terus-menerus setiapitahunnya.iPertumbuhan tersebut dipengaruhi oleh tingginya tingkat keyakinan masyarakat Indonesia terhadap bank syariah, serta bisa dilihatidariipertumbuhaniaset industri perbankanisyariahsaat ini. Berikut grafil pertumbuhan asetiperbankanisyariah. 


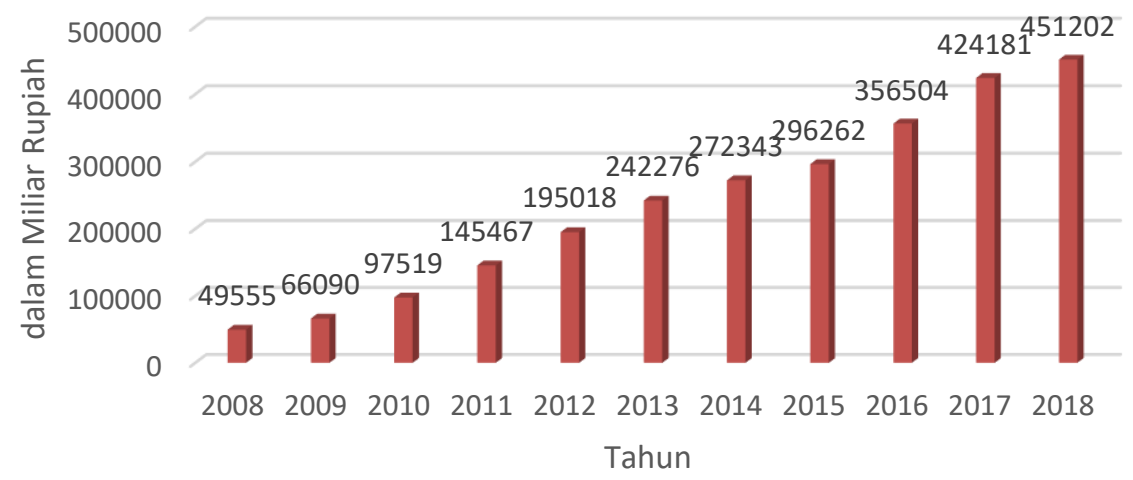

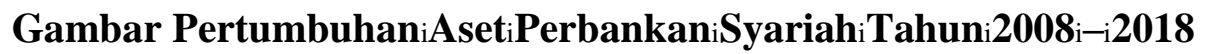

Pertumbuhaniasetibankisyariahimengalamiipeningkataniwalaupunitidakisignifikan, bahkan pertumbuhan aset setiap tahun tersebut cenderung menurun. Pertumbuhan aset pada tahun 20082011 mengalami peningkatan setiap tahunnya sedangkan pada tahun 2013-2015 terjadi penurunan pada pertumbuhan aset yang dimiliki perbankan syariah. Hal yang baik terjadi pada tahun 2016 dimana peningkatan pertumbuhan aset terjadi hingga dua kali lipat tahun sebelumnya. Pada tahun 2017 terjadi peningkatan pertumbuhan aset tetapi penurunan yang signifikan terjadi pada tahun 2018.

Peningkatan pertumbuhan bank syariah di Indonesia didukung oleh kebijakan spinoffdengan dasar UU No. 21 Tahun 2008 tentang Perbankan Syariah. Undang-Undang tersebut menyebutkanbahwaibankiumumikonvensionali(BUK)I

yangimempunyaiiUsahaiUnitiSyariahi(UUS)harus memisahkan diri menjadi bank umum syariah apabila jumlah aset yang dimilikinya mencapai paling sedikit $50 \%$ dari total jumlah aset bank induknya atau 15 tahun saat diberlakukannya Undang-Undang ini (tahun 2023). PeraturaniOtoritasiJasaiKeuanganiNomori64/POJK.03/2016itentangiPerubahaniKegiataniUsaha Bank Konvensional Menjadi Bank Syariah juga berisi mengenai persyaratan dan tata cara perizinan perubahan kegiatan usaha bank tersebut.

Prinsip antara bank konvensional dengan bank syariahmemiliki perbedaan (Arifin, 2009). Bank umum konvensional (BUK) memiliki prinsip yaitu bebas nilai yang berarti uang sebagai alat yang dapat diperjualbelikan serta diperolehnya bunga.Sebaliknya, bank syariah tidak bebas karena uang dijadikan sebagai alat tukar. Hal tersebut memiliki arti bahwa bank syariah tidak memperjualbelikan uang. Perkembangan perbankan syariah di Indonesia memberikan konsekuensi kompetisi yang semakin ketat antar perbankan. Menurut Hanifah (2014) dalam Puspitasari (2018), dengan jumlah bank umum syariah dan bank umum konvensional yang banyak beroperasi di Indonesia maka bentuk pelayanan dan produk yang dihasilkan akan semakin banyak sehingga akan timbul permasalahan. Persaingan yang timbul tidak hanya terjadi antara bank umum konvensional dan bank umum syariah saja, tetapi juga terjadi antar sesama banksyariah maupun sesama bank konvensional. Hal ini menyebabkan peneliti tertarik untuk meneliti bagaimana perbandingan kinerja perbankan konvensional dan perbankan syariah yang melakukan pemisahan (spin-off) dilihat dari segi efisiensi, kualitas aset, dan stabilitas.

Efisiensi yaitu perbandingan dari jumlah suatu input yang dihasilkan. Bankidikatakaniefisienijikaimenggunakanisuatuiunitiyangisedikitidibandingijumlahisuatuiunitinput yang dikeluarkan oleh perusahaan agar mendapatkan output yang lebih besar. Sebaliknya, Banktidak efisien jika tidak bisa bersaing dalam meminjamkan dana kepada masyarakat. Oleh 
karena itu,penilaian efisiensi dinilai penting dikarenakan efisiensi adalah gambaran suatu kinerja perbankan dan menjadikan faktor yang diperhatikan untuk menghadapi risiko dalam kegiatan operasionalnya (Dewanti, 2014).

Kualitas aset adalah semua aset rupiah yang diperoleh oleh bank dengan maksud untuk mendapatkan pendapatan yang diinginkan (Nugroho dkk. 2018). Kualitas aset diatur dalam POJK No. 16/POJK.03/2014 tentang Penilaian Kualitas Aset Bank Umum Syariah dan Unit Usaha Syariah menyatakan bahwa aset bank umum terdiri atas dua, yaitu aset produktif dan aset nonproduktif. Kestabilan sistem perbankan ditentukan berdasarkan keadaan bank yangisehatidanifungsiiperantaraiperbankaniyangidapatiberjalanidalamrangka menyalurkan kredit dan pembiayaan lain kepada dunia usaha. Melaksanakan kebijakan moneter yang efektif serta lancarnya proses perputaran uang ditentukan oleh stabilitas sistem perbankan. Oleh karena itu, upaya untuk menghindari atau mengurangi risiko terjadinya ketidakstabilan perbankan sangatlah diperlukan terutama untuk menghindari kerugian yang besar (www.ojk.go.id).

Berdasarkan penjelasan di atas, pada prinsipnya perbankan syariah dan perbankan konvensional mempunyai tujuan organisasi yang sama yaitu untuk memperoleh keuntungan. Namun yang membedakannya adalah proses operasi yang dijalankan, dimana perbakan konvensional menggunakan bunga sementara perbankan syariah menerapkan bagi hasil melalui transaksi berdasarkan akad-akad tertentu (Rashid \& Jabeen, 2016). Perbandingan yang menggunakan variabel efisiensi, kualitas aset, dan stabilitas pada penelitian ini disebabkan adaperaturan dari Otoritas Jasa Keuangan (OJK) yang mengatur hal tersebut.

Penelitianimengenaiiperbandinganiefisiensi,kkualitasiaset,Idanistabilitasiantaraiperbankanik onvensionalidaniperbankanisyariahisudahipernahidilakukan.iNamun, Ipenelitianisebelumnyaihanyai dilakukanisecaraiumumisajaidanimenunjukkanihasiliyangitidakikonsisten.iPenelitianiiniiberbedaidi karenakanipenelitiberfokusiuntukimengetahuiiperbandinganiefisiensi,Ikualitasiaset,Idanistabilitasi antaraibankiumumikonvensionalidenganibankiumumisyariahiyangitelahimelakukanipemisahani (spi noff)IdiiIndonesiaiperiodeitahuni20132017.iTerdapati11ibankiumumikonvensionaliyangimelakuka nipemisahani(spin-off)imenjadiibankiumumisyariah.i

Penelitian ini mengacu kepada penelitian Beck et al. (2013) dengan menggunakan sampel 22 negara yang menghasilkan kesimpulan yaitu tidak terdapat perbedaan signifikan pada model bisnis diantara kedua bank tersebut. Namun, bank syariah memiliki efisiensi, kualitas aset, dan stabilitasyanglebihibaikidaripadaibankikonvensional.iHasilipenelitianiiniisejalanidenganiyangidilak ukanoleh Sakti dan Mohamad (2018) yang menggunakan bank di Indonesia sebagai sampel yaitu menunjukkan adanya perbedaan yang signifikan pada model bisnis diantara kedua bank.Hasil penelitian yang berbeda ditunjukkan oleh Ahmad dan Rahman (2012) serta Yudistira (2004) yang mengatakan bahwa bank konvensional lebih efisien daripada bank syariah.

Penelitian ini berkontribusi dalam memperdalam pemahaman serta memberikan input untuk pihak manajemen bank dalam hal evaluasi, perbaikan, dan peraturan yang dibuat supaya perbankan di Indonesia bisa menarik investor dan memiliki perkembanganyang lebih baik untuk masa yang akan datang. Indonesia juga berada pada posisi ke-9 sebagai negara yang mempunyai aset keuangan syariah terbesar di dunia serta adanya peraturan yang mewajibkan dilakukan pemisahan (spin-off) untuk Usaha Unit Syariah (UUS) menjadi Bank Umum Syariah (BUS) sebelum tahun 2023.

Denganidemikian, Ipenelitiitertarikiuntukimenelitiilebihilanjutimengenaiiperbandinganibank iumumikonvensionaldan bank umum syariah yang melakukan pemisahan (spin-off) dengan judul "Analisis Perbandingan Efisiensi, Kualitas Aset, dan Stabilitas pada Bank Umum Konvensional 
dan Bank Umum Syariah yang Melakukan Pemisahan (Spin-Off) di Indonesia Periode Tahun 2013-2017".

\section{REVIU LITERATUR \\ TeoriiKeagnenan}

Asimetriiinformasiiadalahisalahisatuiyangimenjadiisebabiterjadinyaiperselisihanikarenai biasiinformasiiyangididapatkaniakibatiadanyaiperbedaanikepentinganidiidalamiorganisasiiterseb uti(Nugrohoietial.,I2018).iKaitannyaidalamipenelitianiiniidijelaskaniDoloksaribui(2012)alamiM $\operatorname{arizkai(2017),I}$

bahwaiterdapatnyaihubunganiantaraimasyarakatisebagaiiprinsipalidanimanajemeniperbankanise bagaiiagenipadaiperusahaaniperbankanidisebabkanikarenaiadanyaiperaturaniyangidikeluarkanip emerintahimelaluiiOJK.iPernyataaniiniimengandungiartiibahwaidalamiperbankanijugaiterdapati hubunganikeagenani(teoriikeagenan)Iantaraimasyarakatisebagaiiprinsipalidanimanajemeniperba nkanisebagaiiagen.iHaliyangidemikianmenjadiidasaribahwasanyaiprincipalimemberikanitanggu ngjawabikepadaiageniberdasarkanikontrakikerjaiyangitelahidisepakatiisesuaiidenganikebijakaniy angitelahidisahkaniolehipemerintahiyaituiberdasarkaniOJK.iSeharusnyaikonflikikepentinganiant araiagenidaniprinsipalitidakiakaniterjadiikarenaimemilikiitujuaniyangisamaiyaituimengimpleme ntasikanimaqasidisyariahi(Elsaidkk.i2018).i

\section{EfisiensiBank}

Efisiensi adalah penggunaan minimum suatu input untuk memperoleh output yang diinginkan (Hsiao et al. 2010). Aspek yang digunakan dalam penentuan kinerja perusahaan salah satunya adalah dengan dilakukannya pengukuran efisiensi. Mokhtar et al. (2008) memaparkan tigaicaraidalamimengukuriefisiensi,ryaituimemaksimalkanioutputsertaikeuntunganidanimeminimal kan biaya.

\section{KualitasiAset}

POJKNo.16/POJK.03/2014itentangiPenilaianiKualitasiAsetiBankiUmumiSyariahidaniUnitiUsah aiSyariahimenyatakanibahwaiasetibankiumumiterdiriiatasidua,Iyaituiasetiproduktifdaniasetinonp roduktif.iAsetiproduktifimerupakanipenanamanidanaibankidalamirupiahimaupunivalutaiasingiun tukimendapatkanipenghasilaniyaituiberbentukipembiayaan,suratiberhargaisyariah,Itagihanideriv atif,Ipenyertaan,Ipenempatanipadaibankilain,Idanibentukipenyediaanidanailainnya.iAsetinonpro duktifiadalahiasetiselainiasetiproduktifiyangiberpotensiimenimbulkanikerugianiberbentukiaguna niyangidiambilialih,Irekeningiantarkantor,I danisuspenseaccount.

\section{Stabilitas}

Stabilitasiekonomiisuatuinegaraimemilikiihubunganidenganiindustriikeuangannyaidisebabkaniol ehikekuatanisektorikeuanganiyangiakaniberdampakikepadaipeningkatanipertumbuhaniekonomii yangilebihicepat,Isehinggaikestabilitasaninegaraitersebutidapatiberjalanidenganibaik.iMenurutiK aufmani(2004),Ihubunganistabilitasiekonomiidenganiindustriikeuanganitidakiselaluimenunjukka nibahwaiketidakstabilaniekonomiimakroidisebabkaniolehiketidakstabilanikeuangan,Itetapiiterjad iikarenaikeduaihaliituiseringiterjadiisecaraibersamaan.iWalaupuniyangiterjadiiadalahiketidaksta bilaniekonomiimakroimerupakanialasaniterjadinyaipermasalahanipadaistabilitasikeuangan. 


\section{PengembanganiHipotesisEfisiensi}

Efisiensiidiperolehidariirasioiperbandinganiantaraioutputdaniinputipadaisuatuiperusahaan.iBanki dapatidikatakaniefisienijikaioutputyangidihasilkanilebihibanyakidaripadaiinputiyangidikeluarkan dalamimenjalankanikegiatanibisnisnya.iEfisiensiibankimenjadiisalahisatuiindikatoripentingidala mimelakukanianalisisikinerjaibankidanihalitersebutidapatimeningkatkaniefektivitasikebijakanipe rbankani(Rozzanii\&I Rahman,I 2013). PendekataniDataiEnvelopmentiAnalysisi(DEA)I cukupiseringidigunakanidalamipenelitianiyangiterkaitidenganiefisiensiiperbankan.iPendekatanii niidilakukanidenganimelakukaniperbandinganiantaraitotalioutputtertimbangi(outputiweighted)I yangidihasilkanidenganitotaliinputitertimbangi(inputiweighted).iAdanyaikelemahaniyangiditemu kaniketikaimenggunakaniDEAiadalahiterdapatiasumsiimengenaiisetiapiunitiinputiatauioutputide ntikdenganiunitilainidalamitipeiyangisama.i

Olehisebabiitu,Iperbedaanitersebutiakaniberdampakikepadaihasiliyangibiasidariipenelitia niitu.iBeckietial.i(2013)dalamipenelitiannyaimenggunakanipendekatanidenganiduaiindikatoriyait uiOverheadi $(\mathrm{OH}) \mathrm{I} \quad$ costidaniCostiIncomeiRatioi(CIR).SemakinitinggiinilaiiratarataibiayaioverheaddaniCIRimakaiituiakanimenggambarkanirendahnyaiefisiensiibankibaikibagii sisiibankisyariahidanikonvensional.iSebaliknyaisemakinirendahinilaiiratarataibiayaioverheaddaniCIRimakaiefisiensiibankisemakinitinggi.iAbdul-Majidietial.i(2010)I mengungkapkanibahwaiukuranibankiakanimempengaruhiitingkatiefisiensiidanioutputyangidihas ilkaniolehibankisyariah.i

HasilipenelitianiyangidilakukaniolehiAhmadidaniRahmani(2012)dapatidisimpulkanibah waiterdapatiperbedaanimengenaiiefisiensiipadaibankiumumikonvensionalidanibankisyariah.iMer ekaimenemukanibahwaibankikonvensionalilebihiefisienidibandingibankiumumisyariahikarenaib ankisyariahitergolongiyangimemilikiitingkatikompleksitasitinggiidaniakanisangatimungkiniuntu kimeningkatkanibiayaisehinggaitingkatiefisiensinyaibankimenurun.iBankisyariahiyangitemasuki lebihibaruiakanilebihiberpotensiiuntukimemilikiibiayaistrukturaliyangilebihibesar.iBourkhisidan iNabii(2013);IJohnesietial.i(2013),I\&ISaktiidaniMohamadi(2018)Idalamipenelitiannyaimenunju kkanihasiliyangiberbeda.iHasilipenelitianitersebutisejalanidenganipenelitianiBeckietial.i(2013).ii Merekaimenemukanibahwaibankisyariahimemilikiitingkatiefisiensiilebihitinggiidibandingibanki konvensional.iDariibeberapaihasilipenelitianitersebut,I makaidapatidikembangkanihipotesis:

$\mathrm{H}_{1 \mathrm{i}}$ :iTerdapatiperbedaaniefisiensiipadaibankiumumikonvensionalidenganibankiumum syariahiyangimelakukanispin-off.

\section{KualitasiAset}

Probabilitasiyangilebihitinggiidimilikiiolehibankidenganiukuranibesaridalamimendapatkanikiner jaiyangilebihibaikidibandingibankiyangiberukuranikecil.iBankiyangiberukuranibesariakanidikel olaisecaraiprofesionalidanimempunyaiiportofolioiasetiyangiterdiversifikasiilebihibaiki(Beckietia 1.i2013).iPenilaianiterhadapikualitasiasetidilakukaniuntukimemberikanipenilaianiterhadapikondis iiasetibankidanikecukupanimanajemeniterhadapirisikoikredit.iHaliiniidapatimenunjukkanikualita siasetidanirisikoikreditiyangidihadapiiolehibankidikarenakaniperbedaaniportofolioidalamipinjam anidaniinvestasiidanaibank.iPenilaianikualitasiasetiproduktifipadaipendanaanibankidilakukanide nganimengklasifikasikanimenjadiikategoriidiibawahistandar,I

diragukaniatauimacet.iHaliiniidigunakanisebagaiisyaraticadanganiminimumdalamimenghapusias etiproduktifiapabilaiterjadiikerugiani(Nugrohoietial,I 2017).

Pengukuranikualitasidapatidilihatidariiloanilossireservesi(LLR).iJikairasioiLLRilebihitin ggiiantaraibankikonvensionalidanibankisyariahimakaibankitersebutiakanimengalamiikerugianiya 
ngilebihibesaridibandingkanidenganibankilainnyaisehinggaikualitasiasetitersebutilebihiburuk.iB eckietial.i(2013),Arissi(2010)I\&ISaktiidaniMohamadi(2018)Iemaparkanidalamipenelitiannyaiyai tuiadaiperbedaanidikeduaibankijikaidilihatidariikualitasiaset.iBankiumumisyariahimemilikiikuali tasiasetiyangilebihibaikikarenaikapitalisasiiyangidilakukanilebihibaikidibandingibankiumumikon vensional.iDariibeberapaihasilipenelitianitersebut,I makaidapatidikembangkanihipotesis:

$\mathrm{H}_{2}$ :iTerdapatiperbedaanikualitasiasetipadaibankiumumikonvensionalidenganibankiumum isyariahiyangimelakukanispin-off.

\section{Stabilitasi}

Perbankanimerupakanisalahisatuikunciipertumbuhaniekonomi.iBankiIndonesiaiselainime njagaikestabilanimoneterijugaimenjagaikestabilaniperbankanidalamipertumbuhaniekonomiiyang iberkelanjutan.iDiiIndonesia,I perbankanikonvensionalidanisyariahibersamasamaimengambiliperanidalamimeningkatkanipertumbuhaniekonomii(Nugrohoietial,I

2017).iKesehatanisuatuiperbankaniakanimencerminkanikestabilaniperbankan.iSistemikeuangani yangimerupakanibagianidariisistemiekonomiisangatiberperanipentingidalamikemajuaniperekono mian.iKetidakstabilanidanitidakiberfungsinyaisistemikeuanganisecaraiefisieniakaniberdampakip adaipendanaaniyangitidakidijalankanidenganibaikisehinggaimemperlambatipertumbuhaniekono mi.iQuagliarielloi(2008)

memaparkanibahwaiperiodeimispricingiasetiakanimenandakanikeuanganiyangitidakistabil,I

kreditimacetimeningkatidanirasioimodaliakanimenurun.iRasioiyangisemakinidekatidenganinolia kanicenderungisemakinirendahidalamimenutupiipotensiikerugian.iHasilipenelitianiBeckietial.i(2 013)I

menyimpulkanibahwaijikaidilihatidariiperformaimakaipadaisaatikrisisibankisyariahilebihibaikidi bandingibankikonvensional,I

dikarenakaniolehikapitalisasiidanikualitasiasetiyangidimilikiilebihitinggi.iMerekaimengambilisa mpelipadaiperiodei1995-

2009,Iyaituipadaisaatikrisisiekonomiiglobalihinggaikrisisiyangiterjadiipadaitiap-

tiapinegaraiyangitermasukisampel.i

Indikatoriyangidigunakaniterkaitipembandinganistabilitasibankiyaituipengembalianiaseti( ROA)IdaniEquityitoiAssetiRatioi(EAR).iROAimenggambarkanikemampuanimanajemenidalami pemanfaatanisumberidayaikeuanganibankidaniinvestasiiagarimendapatkanikeuntungan.iApabilai nilaiiROAimakinitinggi,I

makaibankiakanimemperolehikeuntunganiyangimakinibesar.iStabilitasibankidaniprofitabilitasija ngkaipanjangiperusahaaniditetapkanimenggunakanisalahisatuirasioiyaituiEAR.iJikainilaiiEARiy angimakinitinggiiakanimencerminkanisuatuiperusahaanidenganiaktivitasibisnisiyangisebagianib esaridioperasikanidenganimodaliyangidimilikiiolehipemegangisaham.iEARiyanginilainyaikecil,I akaniterlihatibahwaipembebananiperusahaanikarenaiutangiyangitinggiiuntukibisaimenjalankanik egiatannya.

Berdasarkanipengukuranitersebut,Ipenelitiidapatimenentukaniperbedaanistabilitasidanim anakahiyangilebihistabiliantaraibankikonvensionalidenganibankisyariah.iMenurutipenelitiisebelu mnyaimenunjukkanibahwaibankiumumisyariahilebihistabilidibandingibankiumumikonvensionali (SaktiidaniMohamad,I2018).iNamuniArissi(2010)I

menemukanitidakiadaperbedaanistabilitasiyangisignifikanidiiantaraikeduaijenisibankitersebutDa riibeberapaihasilipenelitianitersebut,imakaidapatidikembangkanihipotesis: 
$\mathrm{H}_{3 \mathrm{i}}$ :iTerdapatiperbedaanistabilitasipadaibankiumumikonvensionalidenganibankiumum isyariahiyangimelakukanispin-off.

\section{METODOLOGIiPENELITIAN JenisiPenelitian}

Penelitianiiniimenggunakanijenisipenelitianistudiideskriptifikomparatif.iDeskriptifikomp aratifimerupakanipenelitianiyangibertujuaniuntukimemperlihatkaniperbandinganipersamaanidani perbedaaniantaraiduaiatauilebihifenomenaiatauipopulasiitertentuiyangibersifatindividu,iorganisa siiindustriiatauiperspektifilainnya.i

\section{PopulasiiDaniSampel}

Penelitianiiniimenggunakanipendekatanitotalisampling, Iartinyaijumlahisampeliyangidigunakani olehipenelitiiakanimemilikiijumlahiyangisamaidenganitotalipopulasi.iBerikutiperbankaniyangite rmasukikeidalamipopulasi.

DaftariBankiUmumiKonvensionalidaniBankiUmumiSyariah

\begin{tabular}{|c|c|c|}
\hline \multirow[b]{2}{*}{ No } & \multirow[b]{2}{*}{ BankiUmumiKonvensional } & BankiUmumiSyariah \\
\hline & & NamaiBank \\
\hline 1 & PT.iBankiMandiri & PT.iBankiSyariahiMandiri \\
\hline 2 & PT.iBNI & PT.iBNIiSyariah \\
\hline 3 & PT.iBankiMega & PT.iBankiMegaiSyariah \\
\hline 4 & PT.iBankiBukopin & PT.iBankiSyariahiBukopin \\
\hline 5 & PT.iBRI & PT.iBRIiSyariah \\
\hline 6 & PT.iBankiPanin & PT.iBankiPaniniSyariah \\
\hline 7 & PT.iBPDiJawaibaratiBanten & PT.iBPDiJawaibaratiBanteniSyariah \\
\hline 8 & PT.iBCA & PT.iBCAiSyariah \\
\hline 9 & PT.iBankiVictoria & PT.iBankiVictoriaiSyariah \\
\hline 10 & PT.iMaybank & PT.iMaybankiSyariah \\
\hline 11 & PT.iBTPN & PT.iBTPNiSyariah \\
\hline
\end{tabular}

\section{JenisiDataiDaniSumberiData}

Penelitianiiniimenggunakanidataisekunder.iDataiyangidigunakaniolehipenelitiiyaituilaporanitahu nani(annualireport)Iperbankan.iLaporanitahunaniyangidigunakanisebagaiisumberidataidalamipe nelitaniiniidiperolehidenganicaraidiunduhidariisitusimasing-masingbank.

\section{TeknikiPengumpulaniData}

Teknikiobservasiidokumentasiidigunakaniolehipenelitiidalamimemperolehidataipadaipenelitianii ni.iTeknikiiniidilakukanidenganimelihatilaporanitahunanibankiyangidipublikasiiolehisetiapiperb ankaniyangidigunakanisebagaiisampelidiisitusiresmiiperusahaanidariitahuni20132017.iPenelitiij ugaimenggunakanibuku,Ijurnal, skripsi,iartikel,iinternet,Idanisumberilainnyaisebagaiidataipendukungidalamipenelitianiini. 


\section{Variabel dan Pengukuran Variabel}

RumusiRasioiyangiDigunakanidalamiPenelitian

\begin{tabular}{|c|c|c|c|}
\hline $\mathrm{No}$ & Kategori & Variabel & Rumus \\
\hline \multirow{2}{*}{1} & \multirow{2}{*}{ Efisiensi } & $\begin{array}{l}\text { Overhead } \\
\text { Cost }\end{array}$ & $\mathrm{OH}$ Cost $=\frac{\text { TotaloperatingCosts }}{\text { TotalAssets }} \times 100 \%$ \\
\hline & & $\begin{array}{l}\text { Cost } \\
\text { Income } \\
\text { Ratio }\end{array}$ & $\mathrm{CIR}=\frac{\text { operatingExpenses }}{\text { OperatingIncome }} \times 100 \%$ \\
\hline 2 & $\begin{array}{l}\text { Kualitas } \\
\text { Aset }\end{array}$ & $\begin{array}{l}\text { Loan Loss } \\
\text { Reserves }\end{array}$ & LLR $=\frac{\text { AllowanceForLoanLosses }}{\text { TotalGrossLoans }} \times 100 \%$ \\
\hline \multirow[b]{2}{*}{3} & \multirow[b]{2}{*}{ Stabilitas } & $\begin{array}{l}\text { Return On } \\
\text { Assets }\end{array}$ & $\mathrm{ROA}=\frac{\text { NetIncomeAfterTax }}{\text { TotalAssets }} \times 100 \%$ \\
\hline & & $\begin{array}{ll}\text { Equity to } \\
\text { Assets } \\
\text { Ratio }\end{array}$ & EAR $=\frac{\text { TotalEquity }}{\text { TotalAssets }} \times 100 \%$ \\
\hline
\end{tabular}

\section{HASIL DAN PEMBAHASAN}

\section{Statistik Deskriptif}

Statistikideskriptifiadalahimetodeiuntuk menggambarkan data secara informatif (Lind et al, 2007).Statistikdeskriptifiditunjukkanidenganifrekuensi, rukuranitendensisentral,Idanidisperse.iFrek uensiimenunjukkaniberapaikaliisubkategoridariisuatuifenomenaitertentuiterjadi.iMean,Imedian,Ida nimodus merupakan penggambaran dari ukuran tendensi sentral, sedangkan jangkauani(range),Ivarians, Istandarideviasi,Idanikisaraniantarkuartilmerupakan penggolongan dari disperse (Sekaran, 2010).(Hasil uji statistik deskriptif terlampir).

\section{Uji Normalitas Data (Kolmogorov-Smirnov)}

Uji normalitas adalah uji untuk mengetahui bentuk distribusi suatu data, yaitu berdistribusi normal atau tidak. Uji ini merupakan uji prasyarat data untuk melakukan analisis dengan menggunakan Uji Beda Dua Rata-Rata (Independent Sampel T-Test). Uji beda tersebut dapat digunakan jika sebuah data lolos uji normalitas. Data yang berdistribusi normal yaitu jika probabilitas atau $\mathrm{p}>0,05$ sedangkan jika probabilitas atau $\mathrm{p}<0,05$ maka data tersebut tidak berdistribusi normal, sehingga menggunakan uji beda Mann Whitney.

Variabel efisiensi dan stabilitas mempunyai signifikansi kecil dari 0,05 yaitu sebesar 0,009 dan 0,001. Data penelitian tersebut tidak berdistribusi normal, sehingga uji beda yang digunakan adalah uji mann-whitney. Variabel kualitas aset berdistribusi normal karena mempunyai signifikansi besar dari 0,05 yaitu 0,819, maka uji beda menggunakan uji t. (Hasil uji normalitas terlampir). 


\section{Uji Hipotesis}

\section{a. Hipotesis Pertama}

Hipotesis pertama menggunakan uji bedaMann Whitney. Rumusan hipotesis pertama (H1) yaitu terdapat perbedaan efisiensi pada bank umum konvensional dengan bank umum syariah yang melakukan spin-off.Hasil uji beda yang terlihat pada hasil pengolahan data bahwa nilai $p$ value sebesar 0,727 yang bernilai di atas 0,05 berarti tidak ada perbedaan efisiensi antara bank umum konvensional dengan bank umum syariah yang melakukan spin-off.Hasil kesimpulannya yaitu hipotesis pertama (H1) ditolak. (Hasil uji hipotesis terlampir)

\section{b. Hipotesis Kedua}

Hipotesis kedua menggunakan uji bedaIndependent Sampel t-Test. Rumusan hipotesis kedua (H2) yaitu terdapat perbedaan kualitas aset pada bank umum konvensional dengan bank umum syariah yang melakukan spin-off.Hasil uji beda yang terlihat pada hasil pengolahan data bahwa hasil nilai sig. $\mathrm{t}$ hitung $>\mathrm{t}$ tabel $(0,950>0,05)$, berarti tidak ada perbedaan kualitas asetantara bank umum konvensional dengan bank umum syariah yang melakukan spin-off.Hasil kesimpulannya yaitu hipotesis pertama (H2) ditolak.(Hasil uji hipotesis terlampir).

\section{c. Hipotesis Ketiga}

Hipotesis ketiga menggunakan uji bedaMann Whitney. Rumusan hipotesis ketiga (H3) yaitu terdapat perbedaan stabilitas pada bank umum konvensional dengan bank umum syariah yang melakukan spin-off.Hasil uji beda yang terlihat pada hasil pengolahan data bahwa nilai asymp. sig. stabilitas yaitu 0,031 . Hal ini menunjukkan nilai $p$ value sebesar $0,031<0,05$ yang berarti terdapat perbedaan stabilitas antara bank umum konvensional dengan bank umum syariah yang melakukan spin-off.Hasil kesimpulannya yaitu hipotesis ketiga (H3) diterima.(Hasil uji hipotesis terlampir).

\section{Pembahasan}

Perbedaan Efisiensi Bank Umum Konvensional dengan Bank Umum Syariah yang Melakukan Pemisahan (Spin-Off)

Hasiliujiibedaipadaihipotesisipertamaitidakimembuktikanibahwaiterdapatiperbedaaniefisiensiantar aibankiumumikonvensionalidenganibankiumumisyariahiyangimelakukanipemisahani(spinoff).iHalit ersebutiterlihatidariihasilipengolahanidataidenganimenggunakaniujiibedaimanniwhitney.iNilaiipival $u e$ isebesari0,727iyangibernilaiidiatasi0,05iberartiitidakiadaiperbedaaniefisiensiantaraibankiumumi konvensionalidenganibankiumumisyariahiyangimelakukanispin-off.

HasilipenelitianiiniisejalanidenganipenelitianiyangidilakukaniolehiDewantii(2014)ryangime njelaskanibahwaitidakiadaiperbedaaniyangisignifikaniantaraibankiumumikonvensionalidanibankiu mumisyariahidalamihaliefisiensi.iHalitersebutikarenaiadanyaikemungkinaniperbankanisyariahiyang iagresifidalamimelakukaniekspansi.iDilakukanipelebaranijaringanibisnisidenganilangkahibanyakny aimembukaikantoricabangibaru.PenelitianiinitidakisejalanidenganipenelitianiElsaidaniUtamii(2015 )ryangimenunjukkanibahwaiterdapatiperbedaaniefisiensiantaraibankiumumikonvensionalidenganib ankiumumisyariahiyangimanaibankiumumikonvensionalilebihiefisien.

\section{Perbedaan Kualitas Aset Bank Umum Konvensional dengan Bank Umum Syariah yang} Melakukan Pemisahan (Spin-Off)

Hasiliujiibedaipadaihipotesisikeduaitidakimembuktikanibahwaiterdapatiperbedaanikualitasiasetiant araibankiumumikonvensionalidenganibankiumumisyariahiyangimelakukanipemisahani(spinoff).iHalitersebutiterlihatidarihasilipengolahanidataidenganimenggunakaniujiibedaiindependentisa 
mpleitest. ${ }_{\text {HHasilinilaiisig.itihitung }}>{ }_{\mathrm{i}} \mathrm{It}_{\mathrm{i}} \mathrm{abel}_{\mathrm{i}}\left(0,950_{\mathrm{i}}>\mathrm{I} 0,05\right)$, Imakaidapatidikatakanibahwaitidakiterdap atiperbedaanikualitasiasetiantaraiBankiUmumiKonvensionalidenganiBankiUmumiSyariahiyangime lakukanipemisahani(spin-off).

HasilipenelitianiiniisejalanidenganipenelitianiyangidilakukaniolehiDewantii(2014)ryangime njelaskanibahwaitidakiadaiperbedaaniyangisignifikaniantaraibankiumumikonvensionalidanibankiu mumisyariahidalamihalikualitasiaset.iHaliniisesuaiidenganiprinsipikehatiatianiyangidilakukaniperb ankanikonvensionalidaniperbankanisyariahipadaisaatimemberikanipembiayaanidanikredit.iAdanyai kemungkinanidisebabkanikarenaikualitasiasetikeduaijenisibankidiaturidalamiPeraturaniOtoritasiJas aiKeuanganiNomori16/POJK.03/2014iTentangiPenilaianiKualitasiAsetiBankiUmumiSyariahidani UnitiUsahaiSyariahidaniPeraturaniOtoritasiJasaiKeuanganiNomori14/POJK.03/2018iTentangiPenil aianiKualitasiAsetiBankiUmumiuntukiMendorong ${ }_{i}$ PertumbuhaniSektoriPerumahanidaniPeningkat aniDevisa.iOlehikarenaiitu,Iperbankanisyariahimaupunikonvensionaliharusimengikutiiperaturaniter sebut,Isehinggaiujiibedaimenunjukkanibahwaitidakiadaiperbedaaniantaraikeduaijenisibank.i

PenelitianiiniitidakisejalanidenganipenelitianiSaktidaniMohamadi(2018)I\&IBeck,IDemirgu cuntidaniMerrouchei(2013)ryangimenyatakanibahwaiterdapatiperbedaanikualitasiasetiyaituibankisy ariahimemilikiikualitasiasetilebihibaikidibandingkanibankikonvensional.i

\section{Perbedaan Stabilitas Bank Umum Konvensional dengan Bank Umum Syariah yang Melakukan Pemisahan (Spin-Off)}

Hasiliujiibedaipadaihipotesisiketigaimembuktikanibahwaiterdapatiperbedaanistabilitasiantaraibanki umumikonvensionalidenganibankiumumisyariahiyangimelakukanipemisahani $\left(\operatorname{spin}_{\text {- }}\right.$

off).iHalitersebutiterlihatiberdasarkanihasilipengolahanidataidenganimenggunakaniujiibedaimanniw

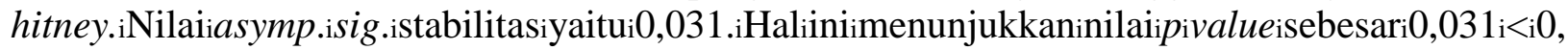
05iyangiberartiiterdapatiperbedaanistabilitasiantaraibankiumumikonvensionalidenganibankiumumis yariahiyangimelakukanispin-off.i

HasilipenelitianiiniisejalanidenganipenelitianiyangidilakukaniolehiSaktiidaniMohamadi(201 8)I\&IBeckietial.i(2013).iMerekaimengatakanibahwaiterdapatiperbedaanisignifikanipadaistabilitasia ntaraibankiumumikonvensionalidenganibankiumumisyariah.iHaliiniimembuktikanikemampuaniper bankanidalamimelakukanipengelolaaniaset.iDilihatidariisegiiROA,I

bankiumumikonvensionalilebihibaikidibandingibankiumumisyariah.iIniimenunjukkanikemampuan ${ }_{i}$ manajemanibankidalamimemanfaatkanisumberidayaiuntukimenghasilkanikeuntungan.iSedangkan $i$ darisegiiEAR, Ibankiumumisyariahilebihibaikidaripadaibankiumumikonvensional.iHalitersebutiber artiibankitersebutidimilikiiolehipemegangisaham.iBankiumumisyariahiyangimemilikiirataratailebihibesaridaripadaibankiumumikonvensionaliakanimenunjukkanimodalibankiumumisyariahi dalamimendanaiiaktivitasiperbankanijauhilebihibesaridaripadaibankiumumikonvensional.iHaliterse butiakanimenandakaniketerikatanidanimotivasiipemegangisahamidiiperbankanisyariahilebihibesari dalamimempengaruhiimanajemeniuntukimeningkatkanikinerja.i

PenelitianiiniiberbedaidenganihasilipenelitianiElsaidaniUtamii(2015)ryangimenunjukkanitid akiterdapatiperbedaanistabilitasiyangisignifikanisecarainilaiiratarataiyangimemperlihatkanibahwaibankiumumisyariahilebihistabilidibandingkanibankiumumikonve nsional.iAkanitetapiiMyrandasarii(2015)Imengatakanibankiumumikonvensionalilebihistabilidiband ingibankiumumisyariah.

\section{SIMPULAN, KETERBATASAN, DAN SARAN Kesimpulan}

Berdasarkan hasil penelitian dan pembahasan, maka peneliti menarik kesimpulan yaitu sebagai berikut. 
a. Uji Mann-Whitney yang digunakan dalam membandingkan variabel efisiensi menunjukkan tidakiterdapatiperbedaaniefisiensiidiantaraibankiumumikonvensionali(BUK)idanibankiumum syariah (BUS) yang melakukan pemisahan (spin-off).

b. Perbandingan variabel kualitas aset dengan menggunakan uji Independent Sample $t$ Testyang menunjukkan hasil penelitian yaitu tidak terdapat perbedaan kualitas aset antara bank umum konvensional (BUK)idanibankiumumisyariahi(BUS)I yangimelakukanipemisahan (spin-off).

c. Uji Mann-Whitney yang digunakan dalam membandingkan variabel stabilitas menunjukkanterdapat $\quad$ perbedaan stabilitas di antaraibankiumumikonvensionali(BUK)danibankiumumisyariahi(BUS)yang melakukan pemisahan (spin-off).

\section{Keterbatasan Penelitian}

Keterbatasan dari penelitian ini yaituhanya menggunakan sampel bankiumumikonvensionali(BUK)rdanibankiumumisyariahi(BUS)I yangimelakukan pemisahan (spin-off), sehingga tidak menggambarkan efisiensi, kualitas aset, dan stabilitas di antara perbankan di Indonesia secara keseluruhan.

\section{Saran}

a. Peneliti selanjutnya diharapkan untuk menambah periode penelitian sehingga dapat memberikan hasil penelitian yang lebih valid.

b. Peneliti selanjutnya dapat menambah dan menggunakan pengukuran variabel lain yang dapat untuk melihat beda antaraibankiumumikonvensionali(BUK)I danibankiumumisyariahi(BUS)yang melakukan pemisahan (spin-off).

\section{DAFTAR PUSTAKA}

Abdul-Majid, M., Saal, David S., \&Battisti, G. (2010). Efficiency in Islamic and Conventional Banking: an International Comparison. Journal of Productivity Analysis. 34:25-43.

Ahmad,I Surayai\&I Rahman,I

AbduliRahimiAbdul.i(2012).iTheiEfficiencyiofiIslamiciandiConventionaliCommercialiBanks iiniMalaysia.iInternationaliJournaliofiIslamiciandiMiddle Eastern $_{\mathrm{i}}$ Finance $_{\mathrm{i} \text { andiManagement. }}$ Arifin, Zainul. (2009). Dasar-Dasar Manajeman Bank Syariah. Jakarta: Gema Insani.

Ariss, Rima Turk. (2010). Competitive Conditions in Islamic and Conventional Banking: a Global Perspective. Review of Financial Economics.

Beck, T., Demirguc-Kunt, A,.\&Merrouche, O. (2013). Islamic vc Conventional Banking : Business Model, Efficiency, and Stability. Journal of Banking and Finance.

Bourkhis, K., \&Nabi, M.S. (2013). Islamic and Conventional Banks' Soundness during The 2007-2008 Financial Crisis. Review of Financial Economics.

Dewanti, T.U. (2014). AnalisisPerbandingan Model Bisnis, Efisiensi, KualitasAset, danStabilitas Bank Syariahdengan Bank Konvensional di Indonesia Periode 2008-2012. Skripsi FE UI.

Elsa,I E.,I Utami,I W., I \&Nugroho, I

L.i(2018).iAAComparisoniofiShariaiBanksiandiConventionaliBanksiiniTermsiofiEfficiency,I AssetiQualityiandiStabilityiiniIndonesiaiforiTheiPeriodi2008-

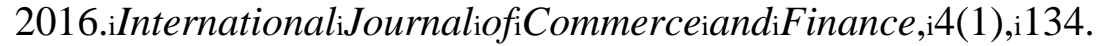

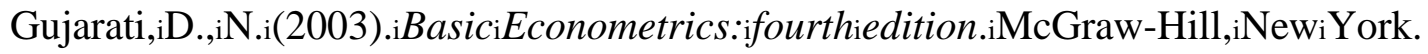


Hsiaoietial.i(2010).iFirstiFinancialiRestructuringiandiOperating ${ }_{i}$ Efficiency:IEvidenceifromiTaiwan

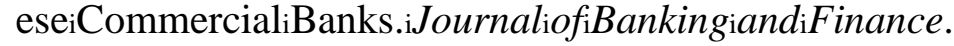

Jensen,IM.iC.,I \& I Meckling,I W.iH.i(1976).iTheoryiofiTheiFirm:I

ManagerialiBehavior, IAgencyiCostSiandiOwnershipiStructure.iJournaliofi FinancialiEconom ics, $\mathrm{i} 3(4), \mathrm{i} 305-360$.

Johnes, I J., I Izzeldin, I M., I \& I Pappas, I

V.i(2013).iAiComparisoniofiPerformanceiofiIslamiciandiConventionaliBanksi2004-

2009.iJournaliofiEconomiciBehaviouriandiOrganization.

Kaufman, George. (2004). Macroeconomic Stability, Bank Soundness, and Designing Optimum Regulatory Structures.Journal of Multinational Finance.

Lind, D.A., Marchal, W.G., Wathen, S.A. (2010). Basic Statistics for Business and Economics. Eight Edition. Mc-GrawHill: New York.

Marizka, Ila. (2017). Pengaruh Capital Adequacy Ratio, Financing To Deposit Ratio, Non

Performing Financing, dan Biaya Operasional Per Pendapatan Operasional Terhadap

Return On Asset Pada Bank Umum Syariah di Indonesia. Skripsi FEB UMP.

Mokhtar,I H.S.A., I Abdullah,I N.,I Alhabsi,I

S.M.i(2008).iEfficiencyiandiCompetitioniofiIslamiciBankingiiniMalaysia.i.JournaliofiHuman omics, $\mathrm{i} 24(1)$.

Myrandasari, Bella. 2015. Analisis Komparasi Stabilitas Perbankan Syariah dan Konvensional

(Bank Umum Devisa Non Go Public di Indonesia).Jurnal Ilmiah Fakultas Ekonomi dan

Bisnis Universitas Brawijaya.3(1).

Nugroho, L., Nurrohmah, S., \&Anasta, L. (2018). Faktor-Faktor yang MempengaruhiOpini Audit Going Concern.JurnalSistemInformasi, Keuangan, Auditing \&Perpajakan, 2(2), 96111.

Nugroho, L., Utami, W., Doktorlina, C. M., Soekapdjo, S., \&Husnadi, T. C. (2017).Islamic

Banking Capital Challenges to Increase Business Expansion (Indonesia

Cases).International Journal of Commerce and Finance, 3(2), 1.

Peraturan Otoritas Jasa Keuangan Nomor 16/POJK.03/2014 tentang Penilaian Kualitas Aset

Bank Umum Syariah dan Unit Usaha Syariah.

Peraturan Otoritas Jasa Keuangan Nomor 64/POJK.03/2016 tentang Perubahan Kegiatan

Usaha Bank Konvensional Menjadi Bank Syariah.

Peraturan Otoritas Jasa Keuangan Nomor 14/POJK.03/2018 tentang Penilaian Kualitas Aset

Bank Umum untuk Mendorong Pertumbuhan Sektor Perumahan dan Peningkatan Devisa.

Puspitasari, Farah Annisa. (2018). Analisis Perbandingan Efisiensi Bank Konvensional dan Bank Syariah di Indonesia.Skripsi FE UII.

Quagliariello,IMario.i(2008).iDoesiMacroeconomyiAffectiBankiStability?iAiReviewiofiTheiEmpe

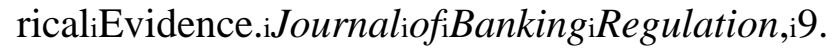

Rashid, A. \& Jabeen, S. (2016). Analyzing Performance Determinants: Conventional versus

Islamic Banks in Pakistan. Borsa Istanbul Review. 16(2).

Rozzani,IN.,I \&I Rahman,I R.A.i(2013).iDeterminantsiofiBankiEfficiency:I

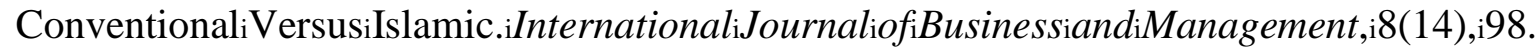

Sakti,I M.R.P.,I \& I Mohamad, , A.i(2018).iEfficiency, I Stability, I andiAssetiQualityiofiIslamicivis-àvisiConvensionaliBanks:I

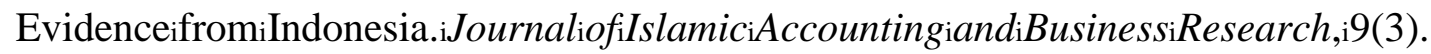

Sekaran, Uma. (2010). Research Methods for Business.Wiley. Jakarta: SalembaEmpat.

Situs Resmi Otoritas Jasa Keuangan.Diakses tanggal 12 Februari 2019.http://www.ojk.go.id. 
Undang-UndangNomor 21 Tahun 2008 tentang Perbankan Syariah.

Yudistira,IDonsyah.i(2004).iEfficiencyininislamiciBanking:I

AniEmiricaliAnalysisiofiEighteeniBanks.iIslamiciEconomiciStudies,, $12(1)$.

Tabel 1

Analisis Deskriptif Variabel Efisiensi

\begin{tabular}{|c|l|c|c|c|c|c|}
\hline Indikator & \multicolumn{1}{|c|}{ Bank } & $\mathrm{N}$ & Minimum & Maximum & Mean & $\begin{array}{c}\text { Std. } \\
\text { Deviation }\end{array}$ \\
\hline \multirow{2}{*}{ OH_COST } & Bank Konvensional & 45 & 1.04 & 5.95 & 3.8306 & 1.08635 \\
& Bank Syariah & 45 & -.55 & 30.40 & 6.4790 & 5.51565 \\
\hline \multirow{2}{*}{ CIR } & Bank Konvensional & 45 & 40.26 & 87.72 & 65.7897 & 11.95280 \\
& Bank Syariah & 45 & -6.46 & 299.10 & 61.4997 & 48.09090 \\
\hline & Valid N (listwise) & 45 & & & & \\
\hline
\end{tabular}

Sumber: data diolah, 2019

Tabel 2

Analisis Deskriptif Variabel Kualitas Aset

\begin{tabular}{|c|c|c|c|c|c|c|}
\hline Indikator & Bank & $\mathrm{N}$ & Minimum & Maximum & Mean & $\begin{array}{c}\text { Std. } \\
\text { Deviation }\end{array}$ \\
\hline \multirow{2}{*}{ LLR } & Bank Konvensional & 45 & .92 & 99.77 & 4.6167 & 14.54188 \\
& Bank Syariah & 45 & .51 & 41.19 & 4.4630 & 7.65443 \\
\hline & Valid N (listwise) & 45 & & & & \\
\hline
\end{tabular}

Sumber: data diolah, 2019

Tabel 3

Analisis Deskriptif Variabel Stabilitas

\begin{tabular}{|c|l|c|c|c|c|c|}
\hline Indikator & \multicolumn{1}{|c|}{ Bank } & $\mathrm{N}$ & Minimum & Maximum & Mean & $\begin{array}{c}\text { Std. } \\
\text { Deviation }\end{array}$ \\
\hline ROA & Bank Konvensional & 45 & .13 & 3.41 & 1.6741 & .91144 \\
& Bank Syariah & 45 & -16.89 & 2.28 & -.4054 & 3.65522 \\
& Valid N (listwise) & 45 & & & & \\
\hline EAR & Bank Konvensional & 45 & 6.00 & 18.00 & 12.6000 & 3.12177 \\
& Bank Syariah & 45 & 1.00 & 421.00 & 24.5556 & 61.43827 \\
\hline & Valid N (listwise) & 45 & & & & \\
\hline
\end{tabular}

Sumber: data diolah, 2019 
Tabel 4

Uji Normalitas

Two-Sample Kolmogorov-Smirnov

\begin{tabular}{|ll|r|}
\hline & & EFISIENSI \\
\hline Most Extreme & Absolute & .244 \\
Differences & Positive & .244 \\
& Negative & -.200 \\
& & 1.640 \\
Kolmogorov-Smirnov Z & & .009 \\
Asymp. Sig. (2-tailed) & & \\
\hline
\end{tabular}

a. Grouping Variable: BANK

Sumber: data diolah, 2019

Tabel 5

Uji Normalitas

Two-Sample Kolmogorov-Smirnov

\begin{tabular}{|ll|r|}
\hline & & KUALITAS_ASET \\
\hline Most Extreme $\quad$ Absolute & .133 \\
Differences & Positive & .133 \\
& Negative & -.089 \\
& .632 \\
Kolmogorov-Smirnov Z & .819 \\
Asymp. Sig. (2-tailed) &
\end{tabular}

a. Grouping Variable: BANK

Sumber: data diolah, 2019

Tabel 6

Uji Normalitas

Two-Sample Kolmogorov-Smirnov

\begin{tabular}{|ll|r|}
\hline & & STABILITAS \\
\hline Most Extreme Differences & Absolute & .300 \\
& Positive & .111 \\
& Negative & -.300 \\
Kolmogorov-Smirnov Z & & 2.012 \\
Asymp. Sig. (2-tailed) & & .001 \\
\hline
\end{tabular}

a. Grouping Variable: BANK

Sumber: data diolah, 2019

Tabel 7 
Uji Mann-Whitney

\begin{tabular}{|l|r|}
\hline & \multicolumn{1}{|c|}{ EFISIENSI } \\
\hline Mann-Whitney U & 3928.000 \\
Wilcoxon W & 8023.000 \\
Z & -.349 \\
Asymp. Sig. (2-tailed) & .727 \\
\hline
\end{tabular}

a. Grouping Variable: BANK

Sumber: data diolah, 2019

Tabel 8

Uji Independent Samples t-Test

\begin{tabular}{|c|c|c|r|r|r|}
\hline & \multicolumn{2}{|c|}{$\begin{array}{c}\text { Levene's } \\
\text { Test for } \\
\text { Equality of } \\
\text { Variances }\end{array}$} & \multicolumn{2}{|c|}{\begin{tabular}{c}
\multicolumn{2}{|c|}{$\mathrm{t}$-test for Equality of } \\
Means
\end{tabular}} \\
\cline { 2 - 7 } & $\mathrm{F}$ & Sig. & $\mathrm{t}$ & $\begin{array}{l}\text { Sig. (2- } \\
\text { tailed) }\end{array}$ & $\begin{array}{c}\text { Mean } \\
\text { Difference }\end{array}$ \\
\hline KUALITAS_ASET Equal variances assumed & .008 & .928 & .063 & .950 & .15376 \\
$\begin{array}{c}\text { Equal variances not } \\
\text { assumed }\end{array}$ & & & .063 & .950 & .15376 \\
\hline
\end{tabular}

Sumber: data diolah, 2019

Tabel 9

Uji Mann-Whitney

\begin{tabular}{|l|r|}
\hline & STABILITAS \\
\hline Mann-Whitney U & 3295.500 \\
Wilcoxon W & 7390.500 \\
$Z$ & -2.160 \\
Asymp. Sig. (2-tailed) & .031 \\
\hline
\end{tabular}

a. Grouping Variable: BANK

Sumber: data diolah, 2019 